\title{
Treatment of refractory supraventricular arrhythmias with flecainide acetate
}

\author{
J A TILL, E ROWLAND, E A SHINEBOURNE, AND D E WARD \\ Department of Paediatric Cardiology, Brompton Hospital, and Department of Cardiology, St George's \\ Hospital, London
}

SUMmARY We treated 13 children aged $0 \cdot 2$ years to $15 \cdot 7$ years (median $7 \cdot 1$ years) with flecainide acetate for refractory symptomatic supraventricular tachycardia. Six children had direct atrioventricular accessory pathways, of whom four had overt Wolff-Parkinson-White syndrome on the 12 lead electrocardiogram, while in the other two the accessory pathway was concealed. Three children had nodal atrioventricular re-entrant tachycardia, two had a re-entrant tachycardia, the exact mechanism of which was not known, one child had ectopic atrial tachycardia, and one had atrial flutter associated with an atrial septal defect. The remaining 12 children had structurally normal hearts. Flecainide $(2 \mathrm{mg} / \mathrm{kg}$ intravenously) resulted in termination of the tachycardia in 11 of the 12 children treated during tachycardia. In 11 of the children successful prophylaxis was achieved with oral flecainide. Side effects occurred in two children during intravenous administration, but there were no side effects with oral treatment. This experience indicates that flecainide, which has not been used extensively in children, is an effective and safe antiarrhythmic agent, capable of terminating and controlling supraventricular tachycardia in children. Furthermore, flecainide may be successful where conventional agents fail.

The incidence of supraventricular tachycardia in children is greater than 1 in $25000 .^{1}$ Treatment with drugs may be problematic. An unknown proportion of these arrhythmias are refractory to conventional treatment and patient and doctor are subjected to a protracted and often unsuccessful process of empirical drug trials while control is attempted. Moreover, some of the agents have unacceptable side effects for children-for example, provocation of asthma with propranolol. There is a need for new effective antiarrhythmic agents, despite the wide range already available.

Flecainide acetate is relatively new and has been used successfully in adults for treatment of ventricular arrhythmias, ${ }^{2}$ atrial fibrillation, atrial tachycardia, atrioventricular nodal re-entrant tachycardia, and atrioventricular re-entrant tachycardia associated with Wolff-Parkinson-White syndrome. ${ }^{3}$ This agent has also been used to control junctional tachycardias in children. ${ }^{4}$

We report our experience in the use of flecainide for treatment of refractory supraventricular in arrhythmias in children.

\section{Patients and methods}

Thirteen children (four boys and nine girls) were treated with flecainide. Their ages ranged from $0 \cdot 2$ to 15.7 years (median $7 \cdot 1$ years) (Table 1 ). Diagnosis was made either on 12 lead electrocardiogram (three children) or at electrophysiological study (10). Three children were found to have atrioventricular nodal re-entrant tachycardia associated with dual atrioventricular nodal pathways at electrophysiological study. In one of these children the tachycardia was incessant, and the other two suffered paroxysmal attacks.

Six children had direct atrioventricular accessory pathways. In four there was overt Wolff-ParkinsonWhite syndrome on the 12 lead electrocardiogram. In two the pathway was concealed. This diagnosis was made during electrophysiological study in one child and on the 12 lead electrocardiogram recorded during tachycardia when the R-R interval lengthened with left bundle branch block in the other child. All six children experienced paroxysmal reentrant tachycardias and in case 1 the tachycardia 
248 Till, Rowland, Shinebourne, and Ward

Table 1 Details of the 13 patients with refractory supraventricular arrhythmias

\begin{tabular}{|c|c|c|c|c|}
\hline $\begin{array}{l}\text { Case } \\
\text { No }\end{array}$ & Age (years)* & Sext & Diagnosis & $\begin{array}{l}\text { Time of presentation to diagnosis } \\
\text { of precise mechanism of } \\
\text { tachycardia (months) } \neq\end{array}$ \\
\hline 1 & $0 \cdot 2$ & M & $\begin{array}{l}\text { Wolff-Parkinson-White syndrome with a concealed } \\
\text { accessory pathway }\end{array}$ & $0 \cdot 5$ \\
\hline 2 & $5 \cdot 6$ & $\mathbf{F}$ & Wolff-Parkinson-White syndrome & 67 \\
\hline 3 & $4 \cdot 6$ & $\mathbf{M}$ & Nodal atrioventricular re-entrant tachycardia & 48 \\
\hline 4 & $13 \cdot 7$ & $\mathbf{F}$ & Ectopic atrial tachycardia & $0 \cdot 7$ \\
\hline 5 & $7 \cdot 3$ & $M$ & Wolff-Parkinson-White syndrome & 12 \\
\hline 6 & $11 \cdot 8$ & $\mathrm{~F}$ & Wolff-Parkinson-White syndrome & 132 \\
\hline 7 & $7 \cdot 1$ & $\mathrm{~F}$ & Wolff-Parkinson-White syndrome & 84 \\
\hline 8 & $3 \cdot 2$ & $\mathrm{~F}$ & Supraventricular tachycardia $\$$ & - \\
\hline 9 & $6 \cdot 4$ & $\mathrm{~F}$ & $\begin{array}{l}\text { Wolff-Parkinson-White syndrome with a concealed } \\
\text { accessory pathway }\end{array}$ & 48 \\
\hline 10 & $15 \cdot 7$ & $\mathrm{~F}$ & Nodal atrioventricular re-entrant tachycardia & 36 \\
\hline 11 & $11 \cdot 0$ & $\mathrm{~F}$ & Supraventricular tachycardia§ & - \\
\hline 12 & $8 \cdot 7$ & M & Nodal atrioventricular re-entrant tachycardia & $0 \cdot 08$ \\
\hline 13 & 1.4 & $\mathrm{~F}$ & Atrial flutter & $0 \cdot 04$ \\
\hline
\end{tabular}

${ }^{*}$ Median age $=7 \cdot 1$ years.

† $\mathbf{M}=$ Male; $\mathbf{F}=$ Female

$\ddagger$ Median time to diagnosis $=\mathbf{3 6}$ months.

$\$$ Precise mechanism unknown.

was so frequent as to be virtually incessant. In five of the six cases tachycardia was typical, using the atrioventricular node during anterograde conduction and the accessory pathway during retrograde conduction. Case 5 had a variety of complex tachycardias in association with an atrioventricular direct accessory pathway and has been described elsewhere. ${ }^{5}$

One child had incessant atrial tachycardia and one incessant atrial flutter. The precise mechanism for the tachycardia was not established in two children. The diagnosis of an atrioventricular re-entrant tachycardia was made on the 12 lead electrocardiogram recorded during tachycardia. Neither showed any evidence of pre-excitation during sinus rhythm. One child had an atrial septal defect (case 13). The other 12 children had structurally normal hearts.
All children were having two to three attacks of symptomatic tachycardia each month, and in most of the children the attacks were more frequent (Table 2). In the older children symptoms during tachycardia were most commonly palpitations and lethargy. Some children experienced chest pain. The youngest infant, aged 7 weeks, rapidly developed congestive heart failure and therefore symptoms of poor feeding and tachypnoea.

All the children had been treated with at least one other antiarrhythmic agent, and most of them had resistant arrhythmias unresponsive to treatment with multiple drugs (Table 3 ) or had developed unacceptable side effects to a number of conventional agents.

Treatment with antiarrhythmic drugs had been withdrawn to allow roughly three elimination half

Table 2 Details of treatment with flecainide acetate in 13 patients with refractory supraventricular arrhythmias

\begin{tabular}{|c|c|c|c|c|c|}
\hline Case No & $\begin{array}{l}\text { Mode of initiation } \\
\text { of tachycardia }\end{array}$ & $\begin{array}{l}\text { Frequency of attacks } \\
\text { before flecainide (per } \\
\text { month) }\end{array}$ & $\begin{array}{l}\text { Outcome of intravenous } \\
\text { treatment }\end{array}$ & $\begin{array}{l}\text { Duration of follow up } \\
\text { (months) }\end{array}$ & $\begin{array}{l}\text { Outcome of oral } \\
\text { treatment }\end{array}$ \\
\hline 1 & Spontaneous & Incessant & Termination & 3 & No attacks \\
\hline 2 & Induced & 2 & Termination & 48 & No attacks \\
\hline 3 & Spontaneous & Incessant & Termination & 32 & Poor control \\
\hline 4 & Spontaneous & Incessant & Termination & 4 & 1 Attack* \\
\hline 5 & Induced & 4 & Termination & 48 & 2 Attacks \\
\hline 6 & Induced & 4 & Termination & 25 & Poor control \\
\hline 7 & Induced & 10 & Termination & 18 & No attacks \\
\hline 8 & Spontaneous & 12 & Termination & 3 & 1 Attack* \\
\hline 9 & Induced & 4 & Termination & 18 & No attacks \\
\hline 10 & Induced & 10 & Termination & 15 & 2 Attacks $\dagger$ \\
\hline 11 & Spontaneous & 3 & Termination & 3 & No attacks \\
\hline 12 & - & 12 & Not treated & 2 & No attacks \\
\hline 13 & Spontaneous & Incessant & $\begin{array}{l}\text { Flutter cycle slowed, but } \\
\text { failed to terminate }\end{array}$ & 12 & No attacks \\
\hline
\end{tabular}

* Attack associated with a reduction in dose.

† Attack associated with a severe chest infection. 
Table 3 Diagnosis and previous treatment with drugs in 13 patients with refractory arrhythmias

\begin{tabular}{|c|c|c|}
\hline Case No & Diagnosis & Previous treatment with drugs \\
\hline 1 & Wolff-Parkinson-White syndrome & Amiodarone, verapamil, digoxin. disopyramide \\
\hline 2 & Wolff-Parkinson-White syndrome & Amiodarone, verapamil, digoxin, disopyramide, propranolol, phenytoin. lignocaine \\
\hline 3 & $\begin{array}{l}\text { Nodal atrioventricular re-entrant } \\
\text { tachycardia }\end{array}$ & Amiodarone, verapamil \\
\hline 4 & Ectopic atrial tachycardia & Verapamil, digoxin, propranolol \\
\hline 5 & Wolff-Parkinson-White syndrome & Verapamil. disopyramide, propranolol. practolol \\
\hline 6 & Wolff-Parkinson-White syndrome & Verapamil. digoxin, propranolol \\
\hline 7 & Wolff-Parkinson-White syndrome & Verapamil, digoxin, propranolol \\
\hline 8 & Supraventricular tachycardia & Digoxin. propranolol \\
\hline 9 & Wolff-Parkinson-White syndrome & Verapamil, propranolol \\
\hline 10 & $\begin{array}{l}\text { Nodal atrioventricular re-entrant } \\
\text { tachycardia }\end{array}$ & Digoxin. propranolol \\
\hline 11 & Supraventricular tachycardia & Verapamil \\
\hline 12 & $\begin{array}{l}\text { Nodal atrioventricular re-entrant } \\
\text { tachycardia }\end{array}$ & Propranolol \\
\hline 13 & Atrial flutter & Amiodarone. digoxin. disopyramide, quinidine \\
\hline
\end{tabular}

lives to elapse before the flecainide was administered. Three children had received amiodarone. Two of these children stopped amiodarone one month before treatment with flecainide. In the case of the youngest patient (case 1) a period of only seven days had elapsed since the withdrawal of amiodarone. Amiodarone could not be detected in the infant's plasma, however, on the day of treatment with flecainide. Furthermore, digoxin concen- trations in this patient were still within the therapeutic range, digoxin having been withdrawn only one elimination half life before treatment with flecainide.

Electrophysiological study was undertaken where necessary for full delineation of refractory supraventricular arrhythmias. Intracardiac studies were performed using standard techniques as described previously. ${ }^{6}$ In all cases the reasons for carrying out

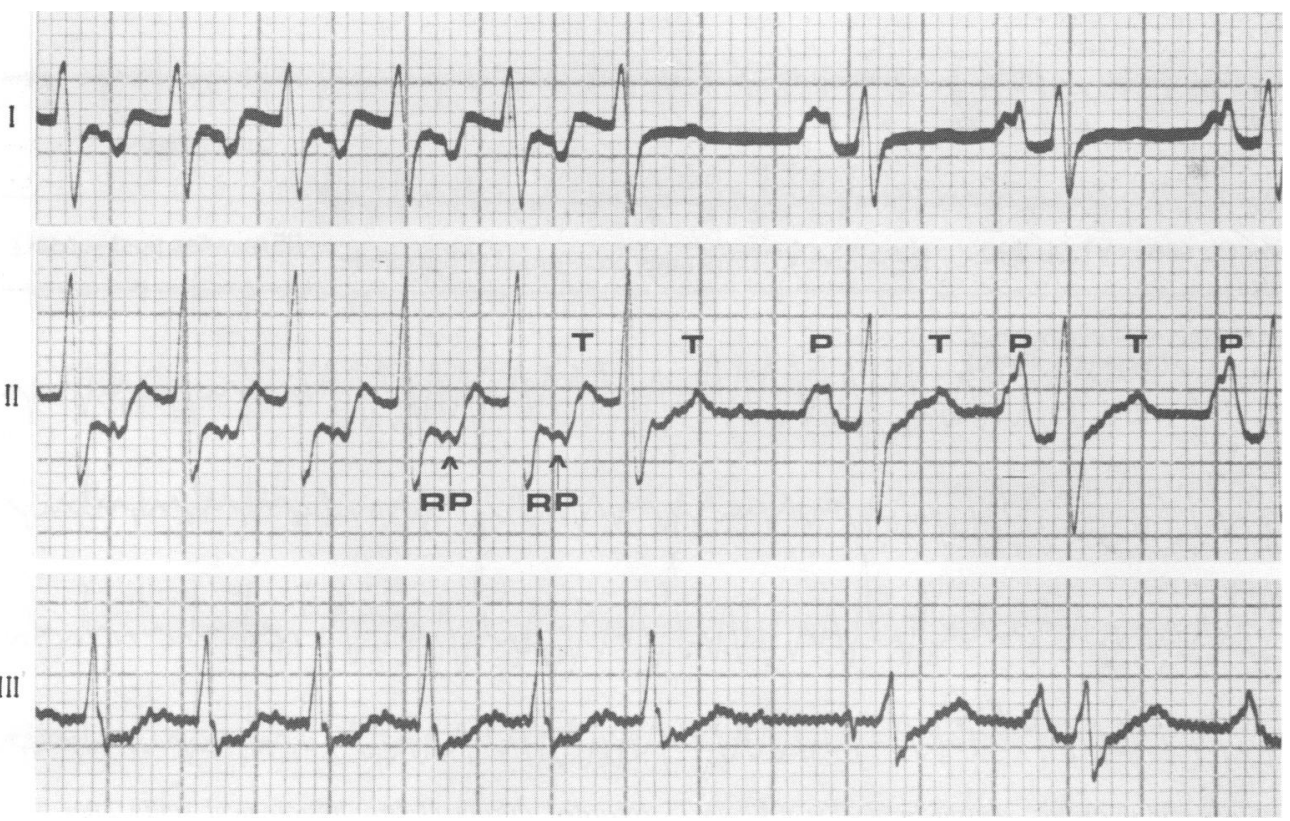

Fig. 1 Electrocardiogram of a case of atrioventricular re-entrant tachycardia, recorded in leads $I$, II, and III, showing termination in the limb involving the accessory pathway (retrograde limb) after intravenous flecainide acetate $2 \mathrm{mg} / \mathrm{kg}$. $P=P$ wave; $R P=$ retrograde $P$ wave; $T=T$ wave. 
the study and for using flecainide were explained to the family and child and informed proxy consent obtained.

Flecainide was infused intravenously during tachycardia in 12 of the children. In six the tachycardia was induced and flecainide given during electrophysiological study. In the other six the tachycardia occurred spontaneously and flecainide was infused while recording a 12 lead electrocardiogram. A dose of $2 \mathrm{mg} / \mathrm{kg}$ was used over a period of not less than five to 10 minutes. The children were later begun on oral flecainide.

\section{Results}

In 11 of the 12 cases where tachycardia was present on administration of flecainide termination occurred within 12 minutes of the start of the infusion (Table 2). In case 13, who had atrial flutter, intravenous flecainide resulted in a slower flutter cycle but failed to terminate the tachycardia. In all 10 cases with re-entrant tachycardia flecainide terminated the tachycardia in the limb involving the accessory pathway. In nine this was the retrograde limb of the circuit (Fig. 1). The antidromic tachycardia in case 5 terminated as a result of atrioventricular block in the anterograde limb.

One child (case 3 ) developed proarrhythmic side effects during intravenous treatment. Only half the dose of flecainide had been given when the tachycardia slowed and terminated in the retrograde limb. Over the next two minutes sinus rhythm remained, but with increasing widening of the QRS complex (right bundle branch block morphology). This then gave way to repetitive multimorphic ventricular tachycardia. Isoprenaline was infused to counter prolonged intramyocardial conduction delay caused by flecainide. Lignocaine and calcium were also administered intravenously. Ventricular tachycardia disappeared 10 minutes after the onset of infusion of flecainide and the QRS complexes gradually returned to normal over several minutes (Fig. 2).

Only one child developed non-cardiac side effects. This child complained of transient nausea during the infusion of flecainide. The nausea disappeared within 10 minutes of stopping the infusion. No side effects were reported on oral treatment. Of the 13 children, all but two suffered fewer

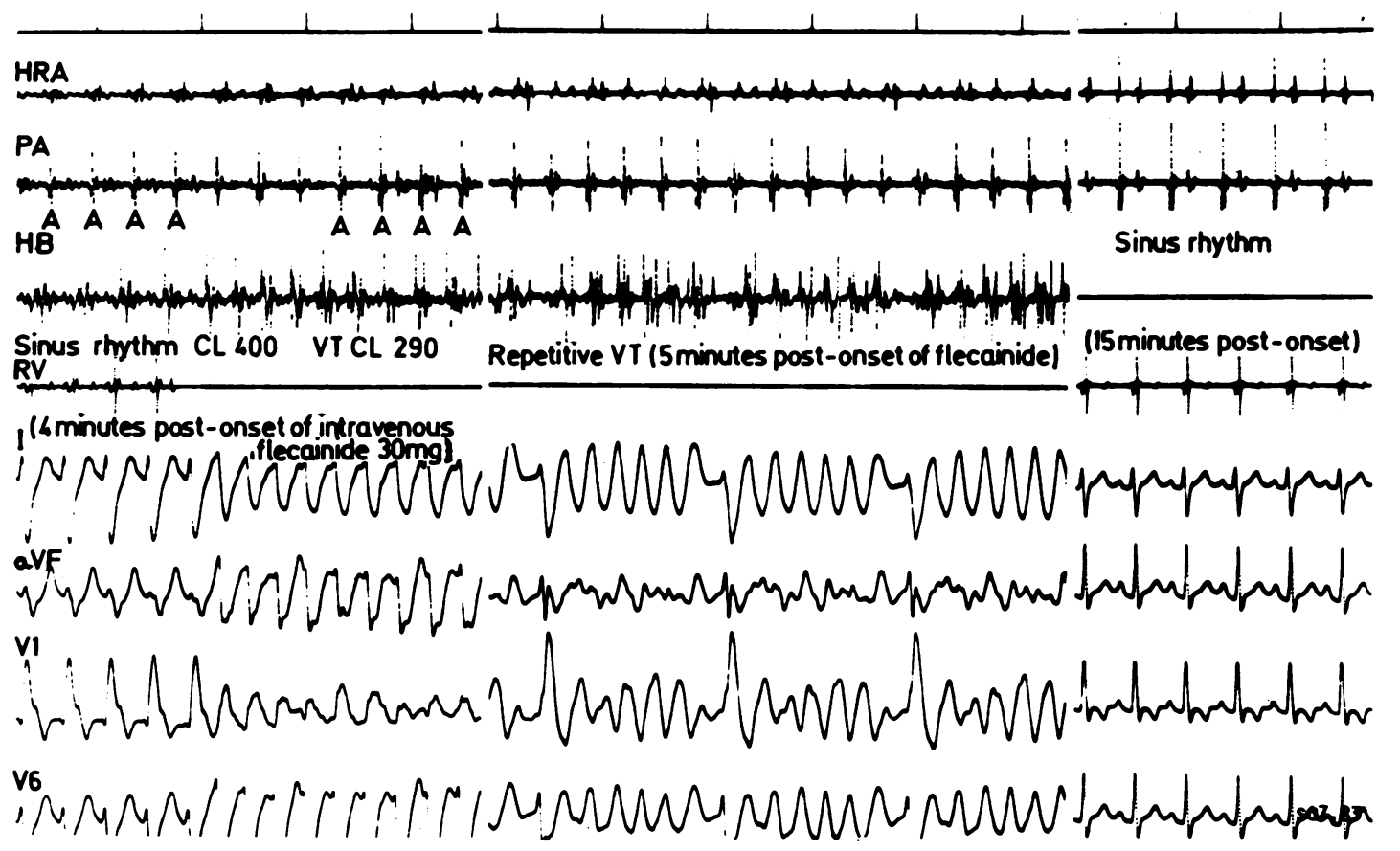

Fig. 2 Repetitive multimorphic ventricular tachycardia (VT) recorded during electrophysiological study after administration of flecainide acetate $(1 \mathrm{mg} / \mathrm{kg})$ with restoration of sinus rhythm. HRA=High right atrial recording; $P A=$ pulmonary artery recording; $H B=H i$ s bundle recording; $I$, aV $F, V I$, and $V 6=$ surface leads; $R V=$ right ventricular apex recording; $A=$ atrial electrogram; $C L=$ cycle length. 
attacks each month than before treatment (median follow up 15 months) (Table 2). In two children flecainide terminated tachycardia acutely but failed to prevent recurrences. Seven children have had no further attacks of tachycardia, including the child with incessant atrial flutter. In this child the atrial flutter failed to terminate during the intravenous infusion but after direct current conversion to sinus rhythm was maintained free of tachycardia with oral treatment.

\section{Discussion}

Flecainide acetate is a relatively new chemical agent with unique properties developed in 1966. It has been classified as a class $1 \mathrm{c}$ drug in the modified Vaughan Williams' classification. ${ }^{7}$ Flecainide slows conduction throughout the heart, having its greatest effect on His bundle conduction. Refractoriness of normal atrial or atrioventricular nodal myocardium is not prolonged, but there is pronounced prolongation of refractoriness in anomalous tissue, such as accessory atrioventricular pathways. ${ }^{8}$

Re-entrant junctional tachycardias are the commonest types of supraventricular tachyarrhythmias in children." Nearly all such circus movement tachycardias involve the atrioventricular node. It is possible to terminate the circuit by delaying conduction through the atrioventricular node. This is the mechanism utilised by more conventional agentsfor example, verapamil. In some situations, however, this may not terminate the tachycardia and may even affect the critical balance of the circuit and thus provide a situation that favours continuation of the tachycardia. In all our patients conventional atrioventricular nodal blocking agents had been used with little or no success. Flecainide may be successful in such situations because of the profound efficacy of the drug in delaying conduction and refractoriness in the accessory pathway. The drug therefore provides an alternative approach to termination of circus movement junctional tachycardias.

In the child with atrial tachycardia flecainide terminated the incessant tachycardia where verapamil, digoxin, and propranolol had failed to do so. Tachyarrhythmias confined to the atria would not be expected to respond well to drugs that exert their major effect on the atrioventricular node. Such drugs had been used in this case because the precise mechanism of the tachycardia was not apparent until an electrophysiological study was undertaken.

The child with atrial flutter was also treated with a number of agents unsuccessfully before long term control was achieved with flecainide. In this case the mechanism of tachycardia was known, and treat- ment with drugs was appropriate but simply failed to control the arrhythmia. Flecainide failed to convert atrial flutter to sinus rhythm in this child. Preliminary reports suggest that flecainide is not particularly effective in the conversion of atrial flutter to sinus rhythm, ${ }^{3}$ and the role of the drug in this situation has yet to be fully evaluated. This child has remained in sinus rhythm for 12 months, however, taking oral flecainide, and the drug may be useful in preventing recurrence.

Flecainide has a prompt onset of action when used intravenously and terminated 11 of the 12 tachycardias within 12 minutes of the start of infusion. The drug was well tolerated both intravenously and orally. One child developed proarrhythmic side effects during intravenous infusion for reasons that are not clear. Such side effects with flecainide have been reported in $7.5 \%$ of treated adults, ${ }^{10}$ being more common in patients with pronounced left ventricular dysfunction. In stable patients, with normal ventricular function, the risk of initiating arrhythmias is likely to be less ${ }^{11}$ and compares favourably with other class 1 agents. ${ }^{12}$ Electrocardiographic monitoring during intravenous administration with prompt termination of the infusion in the event of adverse electrographic signs such as widening of the QRS complex may help to minimise proarrhythmic effects.

Our effects suggest that flecainide will not only terminate but will also prevent recurrence of supraventricular arrhythmias in some children. Successful long term prophylaxis was achieved in 11 of the 13 children (median follow up 15 months) (Table 2).

In many of the children diagnosis of the mechanism of tachycardia was established only after considerable delay (Table 3), and in three cases this resulted in inappropriate treatment with drugs. Electrophysiological study may be helpful in the management of supraventricular tachycardia in children. It has become an established approach in adult practice and has transformed management, allowing not only precise diagnosis of the mechanism of tachycardia but also permitting the assessment of antiarrhythmic drugs. Suitable treatment with drugs may then be chosen based on the supposition that a drug that terminates a tachycardia and prevents reinitiation by intracardiac stimulation is likely to prevent spontaneous recurrence. Our data would support this supposition.

Our experience indicates that flecainide acetate is a safe, quick acting, and effective drug, both in the acute treatment and long term control of supraventricular tachycardia in children. Furthermore, flecainide may be effective where other more conventional agents have failed. Further information is required, but this report suggests that 
flecainide will be a useful drug in the management of supraventricular arrhythmias in children.

\section{References}

' Garson A Jr. Supraventricular tachycardia. In: Gillette P, Garson A Jr, eds. Paediatric cardiac dysrhythmias. New York: Grune and Stratton, 1981:177-253.

2 Anderson J, Stewart J, Perry B, et al. Oral flecainide acetate for the treatment of ventricular arrhythmias. $N$ Engl $J$ Med 1981;305:473-7.

${ }^{3}$ Camm JA, Hellestrand K, Nathan A, Bexton R. Clinical usefulness of flecainide acetate in the treatment of paroxysmal supraventricular tachycardia. Drugs 1985:29(Suppl 4):7-13.

4 Ward DE, Jones S, Shinebourne E. Use of flecainide acetate for refractory junctional tachycardias in children with the WolffParkinson-White syndrome. Am J Cardiol 1986;57:787-90.

5 Ward DE, Bennett DH, Camm AJ. Mechanisms of junctional tachycardia showing ventricular precxcitation. Br Heart $J$ 1984:52:369-76.
" Gillette PC. Advances in the diagnosis and treatment of tachydysrhythmias in children. Am Heart J 1981:102:111-20.

${ }^{7}$ Harrison D. Antiarrhythmic drug classification: new science and practical applications. Am J Cardiol 1985:56:185-7.

${ }^{x}$ Hellestrand K, Bexton R, Nathan A. Spurrel R, Camm J. Acute electrophysiological effects on cardiac conduction and refractoriness in man. Br Heart $J$ 1982:48:140-8.

"Gillette P. The mechanisms of supraventricular tachycardia in children. Circulation 1976;54:133-9.

11 Morganroth J, Horrowitz L. Flecainide: its proarrhythmic effects and expected changes on the surface ECG. Am J Cardiol 1984:53:89-94.

1 Nathan A, Hellestrand K, Bexton R, Banim O, Spurrel R. Camm A. Proarrhythmic effects of the new antiarrhythmic agent flecainide acetate. Am Heart $J$ 1984:107:222-8.

12 Gentzow G, Sullivan J. Extracardiac adverse effects of flecainide acetate. Am J Cardiol 1984;53:101-5.

Correspondence to $\operatorname{Dr} \mathrm{J}$ A Till, Department of Pacdiatric Cardiology, Brompton Hospital, Fulham Road, London SW3 6HP.

Reccived 17 October 1986 